\title{
Surface plasmon enhanced ethylene glycol electrooxidation based on hollow platinum-silver nanodendrites structures.
}

XU, H., SONG, P., FERNANDEZ, C., WANG, J., SHIRAISHI, Y., WANG, C. and DU, Y. 


\section{Highlights}

1. The dendritic Pt-Ag hollow nanocrystals have been successfully engineered.

2. Plasmonic nanostructures can serve as highly efficient photocatalysts.

3. Surface plasmon resonance enhance photoelectrocatalytic EGOR.

4. Facile design over the plasmonic metals endow them superior catalytic activity. 


\title{
Surface plasmon enhanced ethylene glycol electrooxidation based on hollow platinum-silver nanodendrites structures
}

\author{
Hui Xu, ${ }^{a}$ Pingping Song, ${ }^{a}$ Carlos Fernandez, ${ }^{b^{*}}$ Jin Wang, ${ }^{a}$ Yukihide Shiraishi, ${ }^{c}$ Caiqin

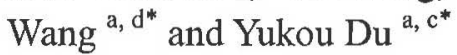 \\ ${ }^{a}$ College of Chemistry, Chemical Engineering and Materials Science, Soochow University, \\ Suzhou 215123, PR China \\ ${ }^{b}$ School of Pharmacy and Life Sciences Robert Gordon University U K \\ ${ }^{c}$ Tokyo University of Science Yamaguchi, Sanyo-Onoda-shi, Yamaguchi 756-0884, Japan \\ ${ }^{d}$ Chemistry Department, University of Toronto, Toronto M5S3H4, RP Canada \\ * Corresponding author: Tel: 86-512-65880089, Fax: 86-512-65880089; \\ E-mail:duyk@suda.edu.cn(Y.Du).
}

\begin{abstract}
The surface plasmon resonance (SPR) effect on noble metals to convert solar energy into chemical has attracted a lot of interest. However, the lack of highly efficient photocatalysts is still the forbidden obstacle as well as their large-scale development. Therefore, we focus on plasmon resonance enhanced electrocatalytic oxidation of liquid fuel employing photocatalysts to develop unique hollow platinum-silver ( $\mathrm{Pt}-\mathrm{Ag}$ ) nanocrystals. The hollow Pt-Ag is formed of nanodendrites $\left(\mathrm{Pt}_{1}-\mathrm{Ag}_{1}\right)$ which display a great enhancement in catalytic activity towards ethylene glycol oxidation with the mass and specific activity found to be: $7045.2 \mathrm{~mA} \mathrm{mg}^{-1}$ and $14.1 \mathrm{~mA} \mathrm{~cm}$, respectively. This is due to: the SPR effect, efficient electronic distribution and synergistic properties, together with the unique hollow dendritic nanostructures. Impressively, the SPR effect also induces the optimum Pt-Ag nanocatalsyst under visible light irradiation conditions to display 1.7 -fold enhancements in catalytic activity compared to that under dark conditions. In addition, 6.2 and 7.0-fold enhancements were obtained when the optimized Pt-Ag was employed as photoelectrocatalyst compared to the commercial $\mathrm{Pt} / \mathrm{C}$. Therefore, we present a unique catalyst which produces a high catalytic activity and long-term stability compared to those previously reported. More importantly, we also introduce a promising approach towards the designing of a plasmonic metal nanocatalyst with ideal nanostructures for liquid fuel oxidations.
\end{abstract}


Keywords: Plasmonic nanostructures; SPR effect; Hollow Pt-Ag dendrites; Ethylene glycol oxidation; Visible light

\section{Introduction}

The production and conversion of solar energy have received much attention in recent years [1]. The use of different photocatalysts to directly convert solar energy into chemical has attracted a great interest. Although most of the photocatalysts are semiconductors, it has also been well demonstrated that plasmonic nanostructures of noble metals such as gold and silver also serve as efficient photocatalysts [2, 3]. Plasmonic metallic nanostructures are featured with their strong interactions with resonant photons via exciting the SPR [4, 5]. In addition, the SPR can be characterized by the collective oscillation of valence electrons induced by resonance photons $[6,7]$. Therefore, the investigation of SPR induced photoelectrocatalytic effect based on plasmonic metallic nanostructures is of vital significance for exploring highly efficient photoelectrocatalysts for electrocatalytic oxidation reactions.

It has been demonstrated that controlling the shape and size of the plasmonic metallic nanocrystals precisely can regulate their properties to meet the requirements of different reactions, for which the SPR is largely dependent on the size and shape of nanocrystals [8]. For instance, the localized surface plasmon resonance (LSPR) wavelengths of $\mathrm{Au}$ can be efficiently tuned from the visible light to near-infrared region by controlling the size and morphology of Au nanoparticles [9-11]. The SPR of $\mathrm{Ag}$ can also be controlled by adjusting the shape and size of the Ag nanoparticles [12]. Accordingly, by manipulating the compositions, sizes and morphologies of the plasmonic metals, it is possible to engineer the nanocatalysts with enhanced photoelectrocatalytic activity and durability towards various chemical reactions [13-15].

The distinctive capability of plasmonic metallic nanostructures to concentrate scatter electromagnetic fields, biosensing, or convert the energy of photons into chemical energy make them suitable for various applications [16-18]. The SPR effects have been widely reported to enhance the catalytic activities of a series of reactions 
such as: water splitting [10], reduction of $\mathrm{CO}_{2}$ [13] and degradation of organic molecules [8] among others. During these processes, the SPR effect of plasmonic metallic nanostructures play a significant role in the substantial enhancement of catalytic activities [18-20]. However, the applications of the photoelectrocatalytic processes in liquid fuel oxidation reactions induced by the SPR effects have remained unexplored.

Therefore, we herein report a facile Pt-Ag hollow nanodendrites synthesis. And the as-prepared hollow Pt-Ag nanodendrites displayed a significant enhancement in the electrocatalytic performances compared with the commercial $\mathrm{Pt} / \mathrm{C}$ catalyst. These outstanding properties are attributed to the unique hollow dendritic structure as well as synergistic and electronic effects between Pt and Ag. More importantly, we took advantage of the plasmonic Ag combination with the SPR to enhance the catalytic activity towards the oxidation of ethylene glycol (EG) by Pt-Ag hollow nanodendrites under visible light illumination. The resulting $\mathrm{Pt}_{1} \mathrm{Ag}_{1}$ nanocatalysts achieved 1.7-fold enhancements in mass and specific activities, showing a class of ideal photoelectrocatalysts towards liquid fuel oxidation.

\section{Experimental section}

\subsection{Chemicals}

Silver nitrate $\left(\mathrm{AgNO}_{3}, 99 \%\right)$, chloroplatinic acid $\left(\mathrm{H}_{2} \mathrm{PtCl}_{6}, 99.9 \%\right)$, hexadecyltrimethylammonium chloride (CTAC, 99\%), L-ascorbic acid (AA, $\mathrm{C}_{6} \mathrm{H}_{8} \mathrm{O}_{6}$, $99 \%$ ), potassium hydroxide $(\mathrm{KOH})$, dehydrate trisodium citrate $\left(\mathrm{Na}_{3} \mathrm{C}_{6} \mathrm{H}_{5} \mathrm{O}_{7} \cdot 2 \mathrm{H}_{2} \mathrm{O}\right)$, acetone $\left(\mathrm{C}_{3} \mathrm{H}_{6} \mathrm{O}, 99 \%\right)$, ethanol $\left(\mathrm{C}_{2} \mathrm{H}_{5} \mathrm{OH}\right.$, A.R. grade, $\left.>99.5 \%\right)$ and $\mathrm{EG}\left(\left(\mathrm{CH}_{2} \mathrm{OH}\right)_{2}\right.$, A.R. grade, $>99.5 \%$ ) were purchased from Sinopharm Chemicals Reagent Co., Ltd, China. Doubly distilled water was used throughout the experiments.

\subsection{Preparation of Pt-Ag hollow nanodendrites}

The Ag seeds were firstly prepared according to the method described by our previously reported work [21]. In the standard synthesis of Pt-Ag hollow nanodendrites, $1.4 \mathrm{~mL} \mathrm{H}_{2} \mathrm{PtCl}_{6}(7.7 \mathrm{mM})$ was firstly injected into $10 \mathrm{~mL}$ aqueous solution in a glass vial, which contained $10 \mathrm{mg}$ CTAC. After vigorous stirring for 10 
$\min , 4 \mathrm{~mL}$ of $\mathrm{AA}(10 \mathrm{mg})$ was added dropwise to the above solution to serve as the reducing agent. After continuous reaction for $3 \mathrm{~min}, 5 \mathrm{~mL}$ of freshly-prepared $\mathrm{Ag}$ seeds were dropped into this aqueous solution. Then, the aqueous solution was violently shaken and capped, and then sonicated at ambient temperature for another 2 h. For comparison, the $\mathrm{Pt}_{1} \mathrm{Ag}_{0.5}$ and $\mathrm{Pt}_{1} \mathrm{Ag}_{1.5}$ hollow nanodendrites were also prepared by tuning the amounts of $\mathrm{Ag}$ seeds to 2.5 and $7.5 \mathrm{~mL}$, respectively, while keeping the other reaction parameters unchanged.

\subsection{Characterizations}

In this work, we firstly used the Tecnai G220 (FEI America) to investigate the morphology and structure of the samples. After that, the FEI Tecnai F20 transmission electron microscope operated at an accelerating voltage of $200 \mathrm{kV}$ was employed to record the scanning transmission electron microscopy (STEM), high-magnification transmission electron microscopy (HR-TEM) and EDX elemental mapping images. An X'Pert-Pro MPD diffractometer (Netherlands PANalytical) with a $\mathrm{Cu} \mathrm{K} \alpha \mathrm{X}$-ray source $(\lambda=1.540598 \AA)$ was used to obtain the powder X-ray diffraction (PXRD) patterns of the samples. The compositions and elemental valences were characterized by X-ray photoelectron spectroscopy (XPS), which was performed on a VG Scientific

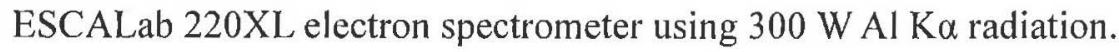

\subsection{Electrochemical measurements}

Cyclic voltammetry (CV) was employed to investigate the electrocatalytic performances carried out in a standard three-electrode system, which included a $\mathrm{Pt}$ wire, glassy carbon electrode (GCE), a saturated calomel electrode (SCE) and as counter, working and reference electrodes, respectively. In the standard preparation of catalysts-coated electrode, the catalysts should firstly be re-dispersed in a mixture solvent containing Nafion and isopropanol and to form a homogeneous catalyst ink by sonicating for $30 \mathrm{~min}$. Next, five microlitres of the dispersion was transferred onto the GC electrode and dried naturally. The $\mathrm{CV}$ was operated using in $1 \mathrm{M} \mathrm{KOH}+1 \mathrm{M} \mathrm{EG}$ at the potential ranging from -0.9 to $0.3 \mathrm{~V}$ with the sweeping rate of $50 \mathrm{mV} / \mathrm{s}$. Every time before examination, the GCE was polished with alumina powder and then rinsed with doubly deionized water and ethanol for several times. Besides, the measurements 
of successive CVs of 500 cycles were also conducted for investigating their long-term durability. To achieve precise results, all the electrochemical measurements were repeated five times. The photocurrent responses of the modified electrode in $1 \mathrm{MEG}$ $+\mathrm{KOH}$ solution were measured with a potential of $-0.2 \mathrm{~V}$ at a scan rate of $50 \mathrm{mV} \mathrm{s}^{-1}$ under visible light illumination. The illumination was interrupted every $100 \mathrm{~s}$. Electrochemical impedance spectroscopy (EIS) measurements were carried out at -0.2 $\mathrm{V}$ with an $\mathrm{AC}$ perturbation signal of $5.0 \mathrm{mV}$ over the frequency range from $100 \mathrm{kHz}$ to $0.1 \mathrm{~Hz}$. It was worth noting that all the visible light in particular, photo-electrochemical measurements were operated by using a xenon lamp (150 W) with UV cut-off filter ( $>400 \mathrm{~nm}$ ) at the distance of $28 \mathrm{~cm}$ to irradiate all the working electrodes.

\section{Results and discussion}

\subsection{Materials characterizations}

The unique Pt-Ag hollow nanodendrites have been prepared by employing a facile wet-chemical method, where CTAC and AA serve as the stabilizers and reducing agents, respectively (See the Experimental Section for details). The as-obtained products were firstly characterized by employing the TEM. The morphological and structural features were characterized via TEM and HAADF-STEM. Fig.1a and b show that the products consist of the uniform hollow nanostructure with the dendrite-like surface. In addition, the nanocrystals were highly dispersed with an average size of $53.8 \mathrm{~nm}$ (Supporting Information, Fig.S1). The HRTEM image of the individual nanodendrite illustrates that the lattice fringe spacing is calculated to be $0.230 \mathrm{~nm}$ (Fig.1c), which is associated with the (111) facet of Pt-Ag alloy [23]. The PXRD patterns of the Pt-Ag hollow nanodendrites exhibit the typical face centered cubic $(f c c)$ structure with the diffraction peaks located between those of the standard Pt and Ag (Fig.1d), which are associated with the HRTEM result, further confirming the formation of Pt-Ag alloy phases in the Pt-Ag hollow nanodendrites. The atomic ratio of Pt/Ag is 52.3/47.7, as revealed by inductively coupled plasma atomic emission spectroscopy (ICP-AES), which is also consistent with the scanning electron 
microscope energy dispersive X-ray spectroscopy (SEM-EDS) (51.4/48.6, Fig.1e). Besides, the composition distribution of $\mathrm{Pt}_{1} \mathrm{Ag}_{1}$ hollow nanodendrites was investigated by employing the EDX elemental mapping analysis, where both $\mathrm{Pt}$ and $\mathrm{Ag}$ were distributed uniformly over the whole Pt-Ag hollow nanodendrite (Fig.1f), as confirmed by the line-scan analysis (Fig.1g). 

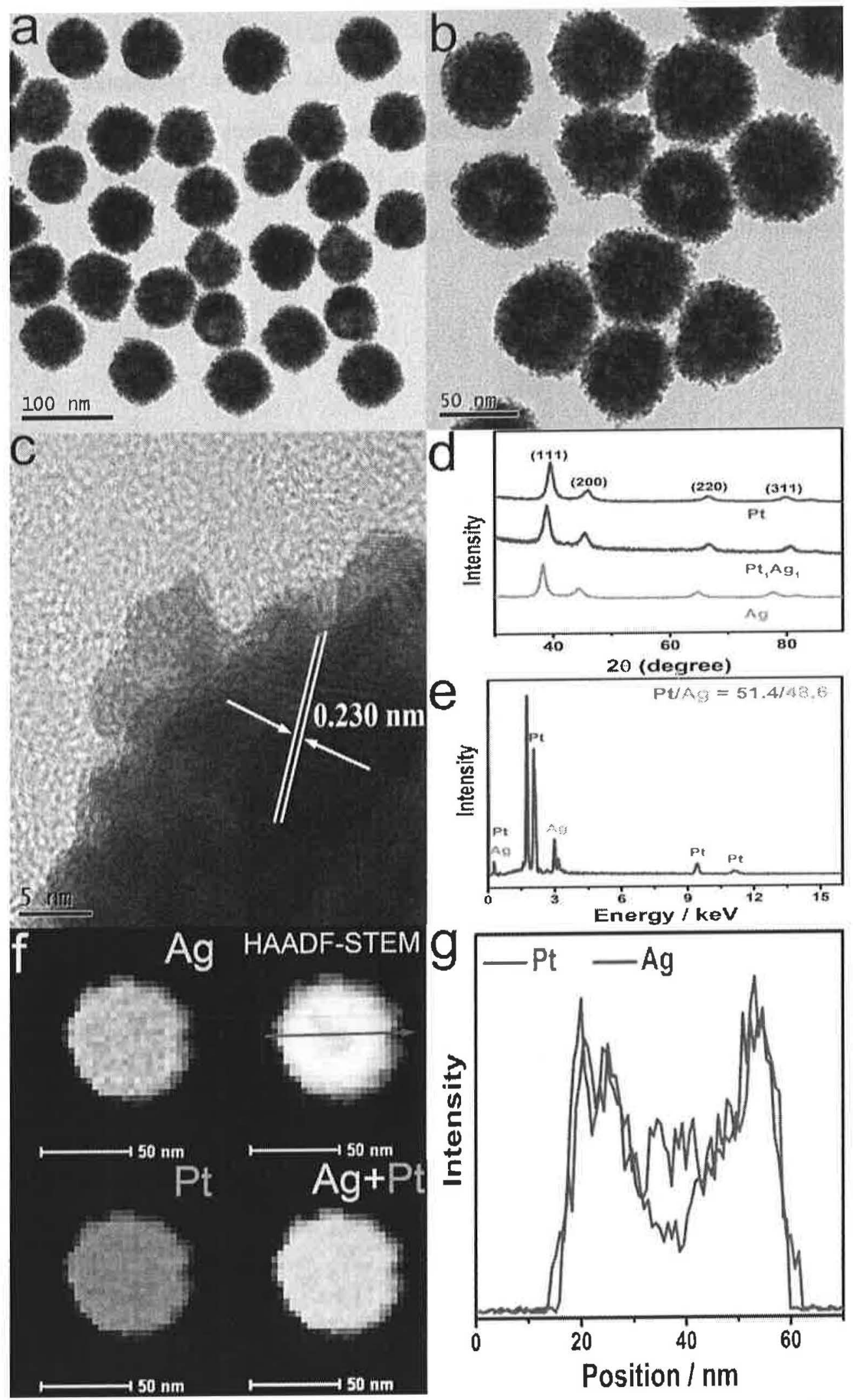

Fig. 1 (a, b) Representative TEM images of $\mathrm{Pt}_{1} \mathrm{Ag}_{1}$ hollow nanodendrites with different magnifications. (c) HRTEM image of an individual $\mathrm{Pt}_{1} \mathrm{Ag}_{1}$ hollow nanodendrite. (d) XRD patterns 
of $\mathrm{Pt}_{1} \mathrm{Ag}_{\mathrm{I}}$ hollow nanodendrites, $\mathrm{Pt}$ and $\mathrm{Ag}$. (e) The TEM-EDX elemental mapping, HAADF-STEM and corresponding ( $\mathrm{f}$ ) line-scan of individual $\mathrm{Pt}_{1} \mathrm{Ag}_{1}$ hollow nanodendrites for element distribution analyses.

Moreover, in order to understand the compositions and elemental valences of the $\mathrm{Pt}_{1} \mathrm{Ag}_{1}$ hollow nanodendrites, the XPS measurements were also employed. As displayed in Fig.2a, the typical peaks at the binding energy (B.E.) of 71.5 and $74.3 \mathrm{eV}$ were assigned to the Pt $4 f_{7 / 2}$ and $P t 4 f_{5 / 2}$ states, respectively. The XPS of $P t 4 f_{7 / 2}$ in the $\mathrm{Pt}_{1} \mathrm{Ag}_{1}$ hollow nanodendrites shifted positively to a higher B.E. and $\mathrm{Ag} 3 \mathrm{~d}$ shifted to a lower B.E. compared with that of standard Pt and $\mathrm{Ag}$, indicating the changes in the electronic structure, which may be attributed to the occurrence of charge transfer from Ag to Pt [24-26]. More importantly, both of the metallic states of Pt and Ag (Fig.2b) were the predominant states in $\mathrm{Pt}_{1} \mathrm{Ag}_{1}$ hollow dendrites.

Next, we analyzed the optical properties of the as-obtained $\mathrm{Pt}_{1} \mathrm{Ag}_{1}$ hollow nanodendrites, by measuring the UV-vis adsorption spectra of the samples, as is displayed in Fig.2c. The $\mathrm{Pt}_{1} \mathrm{Ag}_{1}$ hollow nanodendrites showed an absorption edge at ca. $420 \mathrm{~nm}$, which is associated with the adsorption of $\mathrm{Ag}$ nanoparticles, revealing the distinct absorptions of visible light [27]. While the adsorption edge at $c a$. $650 \mathrm{~nm}$ may be ascribed to some unremoved residues. These results suggest that the as-prepared PtAg hollow nanodendrites catalyst possess the outstanding optical properties, which might be beneficial for photoelectrocatalytic ethylene glycol oxidation reaction (EGOR). In addition, we conducted the photocurrent response measurement to study the photoelectric properties of the resulted $\mathrm{Pt}_{1} \mathrm{Ag}_{1}$ hollow nanodendrites. Fig.2d showed the photocurrent-time (I-t) curve on the $\mathrm{Pt}_{1} \mathrm{Ag}_{1}$ hollow nanodendrites modified electrode. Remarkably, a responsive photocurrent with intensity of $c a .200$ $\mathrm{mA} \mathrm{mg}{ }^{-1}$ was observed for the EGOR when the electrode was upon visible light illumination. Besides, the photocurrent response was also repeatable during on/off cycles upon light illumination, indicating that the SPR and electronic effects between $\mathrm{Ag}$ and Pt were favorable for the enhancement of current density [28]. 

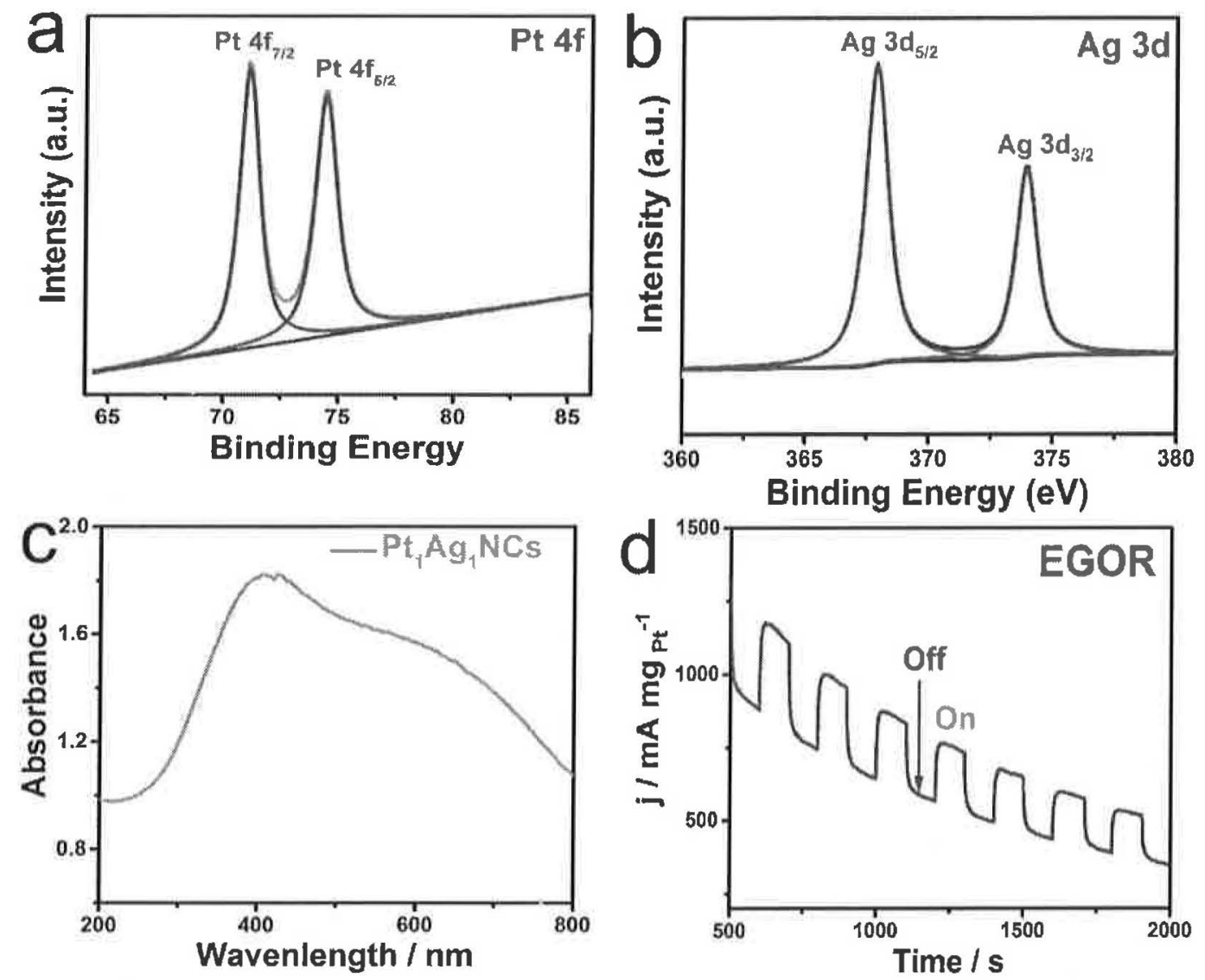

Fig. 2 The XPS spectra of (a) $\mathrm{Pt} 4 \mathrm{f}$ and (b) $\mathrm{Ag} 3 \mathrm{~d}$ in $\mathrm{Pt}_{1} \mathrm{Ag}_{\mathrm{I}}$ hollow nanodendrites. (c) UV-vis spectra of dendritic $\mathrm{Pt}_{1} \mathrm{Ag}_{1}$ hollow nanodendrites, and (d) photocurrent responses of $\mathrm{Pt}_{1} \mathrm{Ag}_{1}$ hollow nanodendrites towards EGOR in $1 \mathrm{M} \mathrm{EG}$ and $1 \mathrm{M} \mathrm{KOH}$ solution at a potential of $-0.2 \mathrm{~V}$ under visible light illumination. The illumination from a Xe lamp was interrupted every $100 \mathrm{~s}$.

To uncover the influences of composition on the final shape, we herein synthesized the other two types of $\mathrm{Pt}_{1} \mathrm{Ag}_{1.5}$ and $\mathrm{Pt}_{1} \mathrm{Ag}_{0.5}$ hollow nanodendrites by simply varying the amount of $\mathrm{Ag}$ seeds while keeping the concentration of $\mathrm{H}_{2} \mathrm{PtCl}_{6}$ solution the same. According to the Fig.S2 (Supporting Information), $\mathrm{Pt}_{1} \mathrm{Ag}_{1}$ hollow nanodendrites were similar to both $\mathrm{Pt}_{1} \mathrm{Ag}_{1.5}$ and $\mathrm{Pt}_{1} \mathrm{Ag}_{0.5}$, indicating the synthesis of Pt-Ag hollow nanodendrites was not dependable on the atomic ratio.

\subsection{Electrochemical tests}

The visible-light-enhanced electrocatalytic oxidation reaction can be applied due to the distinctive hollow dendritic nanostructure, optical properties and the strong SPR effects of the resulted Pt-Ag hollow nanodendrites. Therefore, we herein chose the electrocatalytic oxidation of EG to evaluate the photoelectrocatalytic properties of the dendritic Pt-Ag hollow nanodendrites under the visible light irradiation. The $\mathrm{CV}$ 
operated in $1 \mathrm{M} \mathrm{KOH}$ solution (Fig.3a) was significant for evaluating the electrochemically active surface areas (ECSA) of the electrocatalysts, which can provide some crucial information regarding the number of available active sites. Therefore, a higher ECSA value means more available surface active sites $[29,30]$. The ECSA value for $\mathrm{Pt}_{1} \mathrm{Ag}_{1}$ hollow nanodendrites was calculated to be $50.2 \mathrm{~m}^{2} \mathrm{~g}^{-1}$, which was much higher than those of $\mathrm{Pt}_{1} \mathrm{Ag}_{0.5}$ hollow nanodendrites $\left(46.2 \mathrm{~m}^{2} \mathrm{~g}^{-1}\right)$ and $\mathrm{Pt}_{1} \mathrm{Ag}_{1.5}$ hollow nanodendrites $\left(48.3 \mathrm{~m}^{2} \mathrm{~g}^{-1}\right)$ (Fig.3b). The higher ECSA of $\mathrm{Pt}_{1} \mathrm{Ag}_{1}$ hollow nanodendrites was attributed to the combination of the roughly dendritic surface and hollow nanostructures [31].
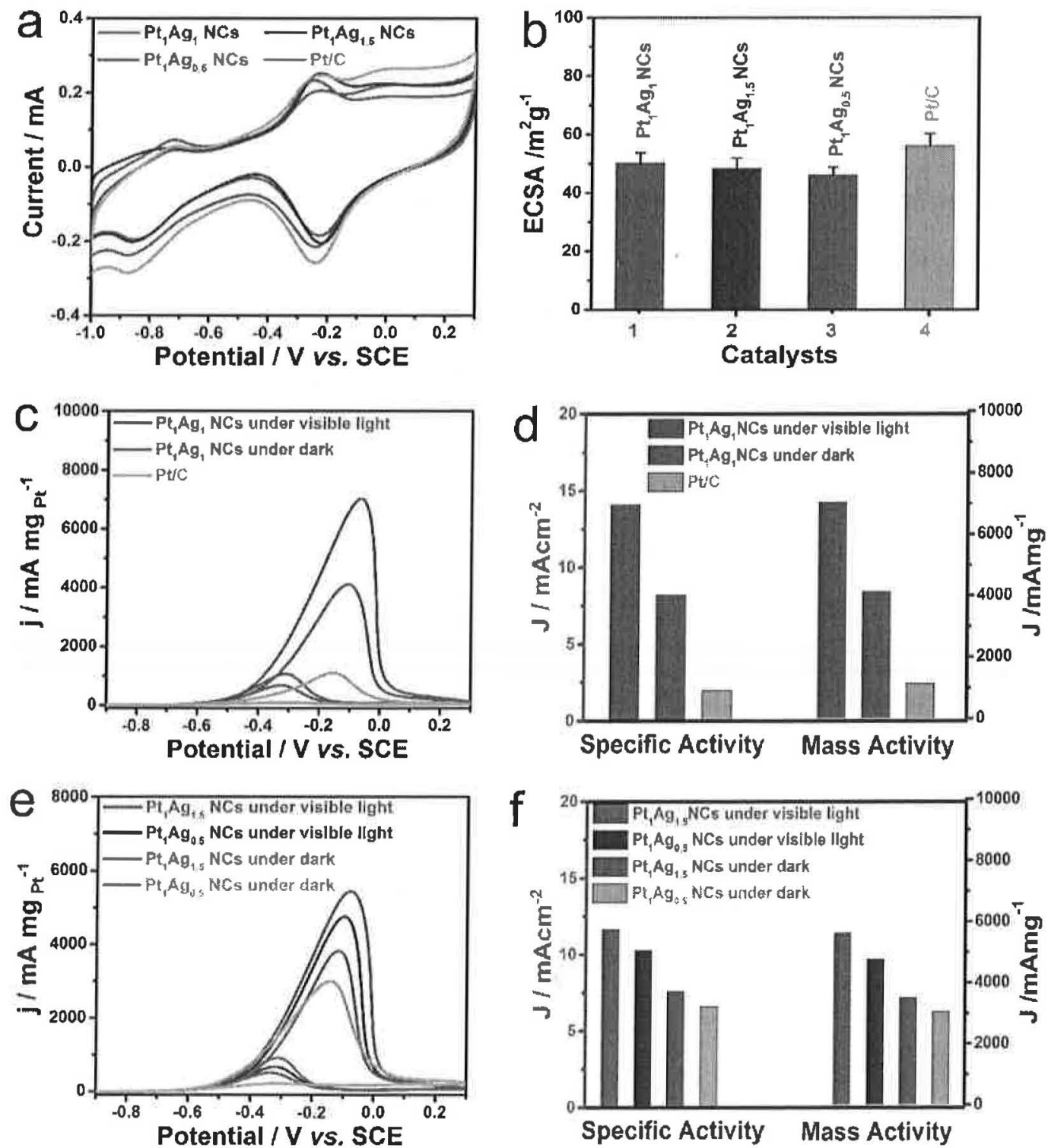

Fig. 3 (a) $\mathrm{CV}$ curves of $\mathrm{Pt}_{1} \mathrm{Ag}_{1}, \mathrm{Pt}_{1} \mathrm{Ag}_{1.5}, \mathrm{Pt}_{1} \mathrm{Ag}_{0.5}$ hollow nanodendrites and commercial $\mathrm{Pt} / \mathrm{C}$ in 1 
$\mathrm{M} \mathrm{KOH}$ solution. (b) The calculated ECSA of $\mathrm{Pt}_{1} \mathrm{Ag}_{1}, \mathrm{Pt}_{1} \mathrm{Ag}_{1.5}, \mathrm{Pt}_{1} \mathrm{Ag}_{0.5}$ hollow nanodendrites and commercial $\mathrm{Pt} / \mathrm{C}$. (c) $\mathrm{CV}$ curves of $\mathrm{Pt}_{1} \mathrm{Ag}_{1}$ hollow nanodendrites under visible light illumination and dark, as well as commercial $\mathrm{Pt} / \mathrm{C}$. (d) The calculated specific and mass activities $\mathrm{Pt}_{1} \mathrm{Ag}_{\mathrm{I}}$ hollow nanodendrites under visible light illumination and dark, as well as commercial $\mathrm{Pt} / \mathrm{C}$ towards EGOR. (e) $\mathrm{CV}$ curves of $\mathrm{Pt}_{1} \mathrm{Ag}_{1.5}, \mathrm{Pt}_{1} \mathrm{Ag}_{0.5}$ hollow nanodendrites towards EGOR under visible light illumination and dark. (f) The calculated specific and mass activities of $\mathrm{Pt}_{1} \mathrm{Ag}_{1.5}$, $\mathrm{Pt}_{1} \mathrm{Ag}_{0.5}$ hollow nanodendrites towards EGOR under visible light illumination and dark condition were illustrated. These electrochemical measurements were repeated five times to achieve precise results.

The electrocatalytic performances of the Pt-Ag hollow nanodendrites were then carried out in $1 \mathrm{M} \mathrm{KOH}$ and $1 \mathrm{M} \mathrm{EG}$ solution at the sweeping rate of $50 \mathrm{mV} / \mathrm{s}$. For comparison purposes, the peak current densities were normalized to both the ECSA and the mass of Pt loading on the surface of the modified electrodes. As it can be seen in Fig. $3 \mathrm{c}$, the $\mathrm{Pt}_{1} \mathrm{Ag}_{1}$ hollow nanodendrites displayed a remarkably superior peak current density under visible light irradiation than that under dark conditions. Fig.3d shows the histogram for the specific and mass activities of commercial $\mathrm{Pt} / \mathrm{C}$ and $\mathrm{Pt}_{1} \mathrm{Ag}_{1}$ hollow nanodendrites under visible light irradiation or dark conditions. Among these, the $\mathrm{Pt}_{1} \mathrm{Ag}_{1}$ hollow nanodendrites under visible light irradiation displayed the highest mass and specific activities of $7045.2 \mathrm{~mA} \mathrm{mg}^{-1}$ and $14.1 \mathrm{~mA} \mathrm{~cm}^{-2}$. In addition, 6.2 and 7.0-fold enhancements were found compared to those of the commercial Pt/C (1135.2 $\mathrm{mA} \mathrm{mg}^{-1}$ and $2.05 \mathrm{~mA} \mathrm{~cm}{ }^{-2}$ ). More interestingly, the $\mathrm{Pt}_{1} \mathrm{Ag}_{1}$ hollow nanodendrites under visible light irradiation also displayed 1.7 times higher than under dark (4129.1 $\mathrm{mA} \mathrm{mg}^{-1}$ and $\left.8.2 \mathrm{~mA} \mathrm{~cm}^{-2}\right)$.

The electrocatalytic activities of the other two types of Pt-Ag hollow nanodendrites with different compositions were also investigated. As it can be seen in Fig. $3 e$ and $f$, both $\mathrm{Pt}_{1} \mathrm{Ag}_{1.5}$ and $\mathrm{Pt}_{1} \mathrm{Ag}_{0.5}$ nanocatalysts displayed excellent electrocatalytic performances towards EGOR under visible light irradiation with the specific activities found to be 11.7 and $10.3 \mathrm{~mA} \mathrm{~cm}^{-2}$, which arel.54 and 1.56 times higher than those under dark conditions, respectively. Apart from the specific activity, both $\mathrm{Pt}_{1} \mathrm{Ag}_{1.5}$ and $\mathrm{Pt}_{1} \mathrm{Ag}_{0.5}$ hollow nanodendrites also displayed an enhancement in mass activity, $5628.7 \mathrm{~mA} \mathrm{mg}^{-1}$ and $4756.8 \mathrm{~mA} \mathrm{mg}^{-1}$ towards EGOR when the modified electrodes were upon the visible light irradiation. The electrocatalytic activities towards EGOR were enhanced greatly by the SPR effects, unique dendritic 
structure and the synergistic properties between $\mathrm{Pt}$ and $\mathrm{Ag}[32,33]$.
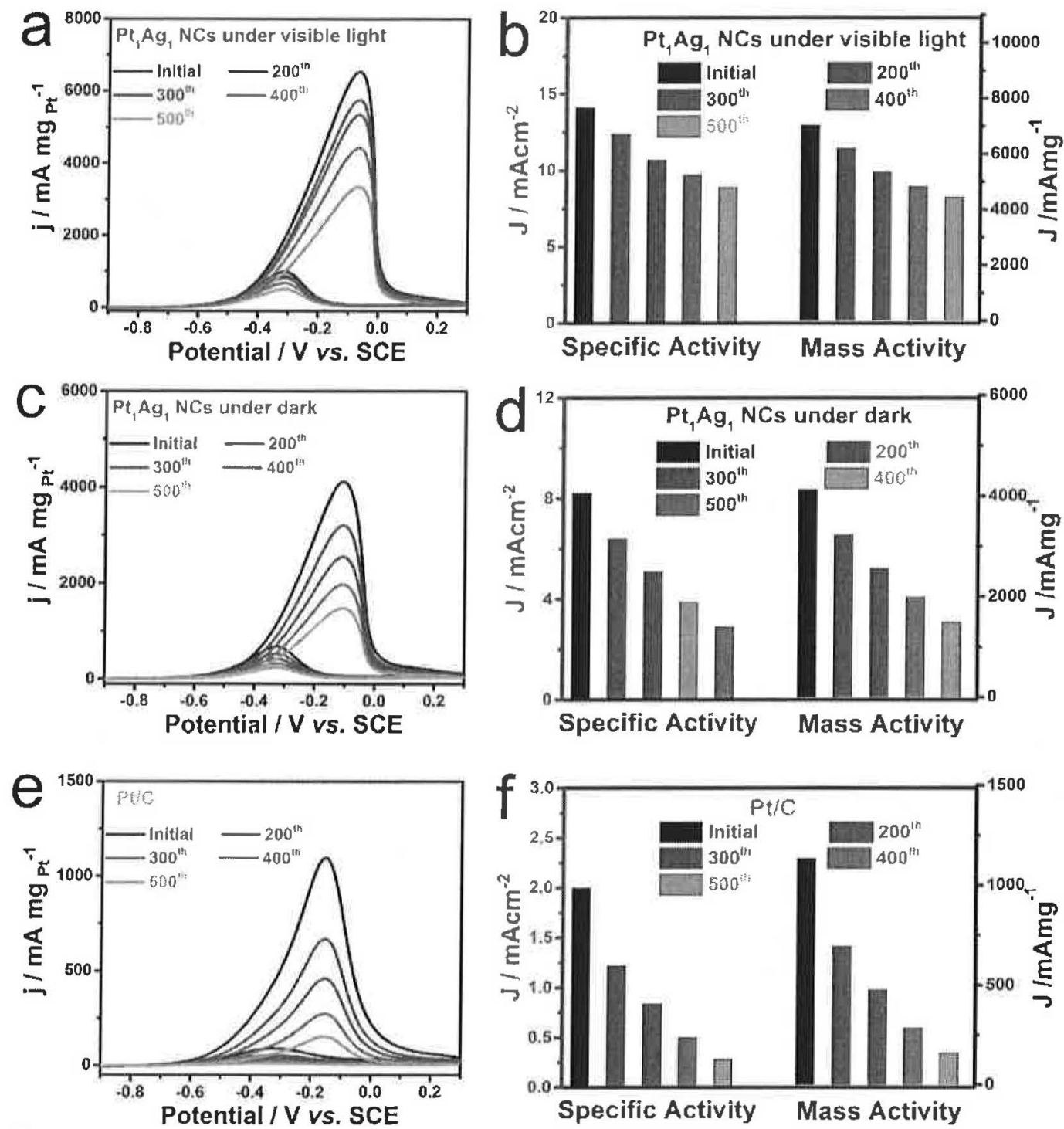

Fig.4 Durability comparison of ( $\mathrm{a}$ and $\mathrm{b}$ ) $\mathrm{Pt}_{1} \mathrm{Ag}_{0.5}$ hollow nanodendrites under visible light irradiation, (c and $\mathrm{d} \mathrm{Pt}_{1} \mathrm{Ag}_{0,5}$ hollow nanodendrites under ambient reaction and (e and $\mathrm{f}$ ) commercial Pt/C for the successive CVs of $200^{\text {th }}, 300^{\text {th }}, 400^{\text {th }}$ and $500^{\text {th }}$ cycles together with the retained specific and mass activities. These electrochemical measurements were repeated five times to achieve precise results.

The durability of the catalyst is also another significant parameter for evaluating the properties of an electrocatalyst in fuel cells. An electrocatalyst with better durability means a much longer lifetime, which is crucial for practical applications [34]. Therefore, we conducted the continuous 500 cycles $\mathrm{CV}$ to investigate their electrocatalytic durability, which were carried out in the solution of $1 \mathrm{M} \mathrm{KOH}+1 \mathrm{M}$ EG solution. According to the Fig.4, although the peak current densities of these 
catalysts decayed rapidly in the initial period, the $\mathrm{Pt}_{1} \mathrm{Ag}_{1}$ hollow nanodendrites upon the visible light irradiation displayed the slowest current decay over time and retained the highest activity among these catalysts after 500 cycles. For more detailed comparison, the normalized current densities of these electrocatalysts are also recorded. As seen, the $\mathrm{Pt}_{1} \mathrm{Ag}_{1}$ hollow nanodendrites nanocatalysts under visible light irradiation retained the catalytic activities of $63.1 \%$ of the initial value towards EGOR, which is much higher than that of commercial Pt/C (14.3\%) and $\mathrm{Pt}_{1} \mathrm{Ag}_{1}$ hollow nanodendrites (36.2 \%) under dark conditions. The retained mass and specific activities of $\mathrm{Pt}_{1} \mathrm{Ag}_{1}$ hollow nanodendrites nanocatalysts under visible light irradiation were calculated to be $4438.5 \mathrm{~mA} \mathrm{mg}^{-1}$ and $8.9 \mathrm{~mA} \mathrm{~cm}^{-2}$, respectively, both of which are much higher than the other electrocatalysts, indicating the superior long-term stability. The greatly enhanced durability of $\mathrm{Pt}_{1} \mathrm{Ag}_{1}$ hollow nanodendrites upon the visible light irradiation can mainly be ascribed to the highly exposed surface active sites, synergistic and electronic effects between $\mathrm{Pt}$ and $\mathrm{Ag}$, as well as the photoelectrical synergistic effects from SPR effects.

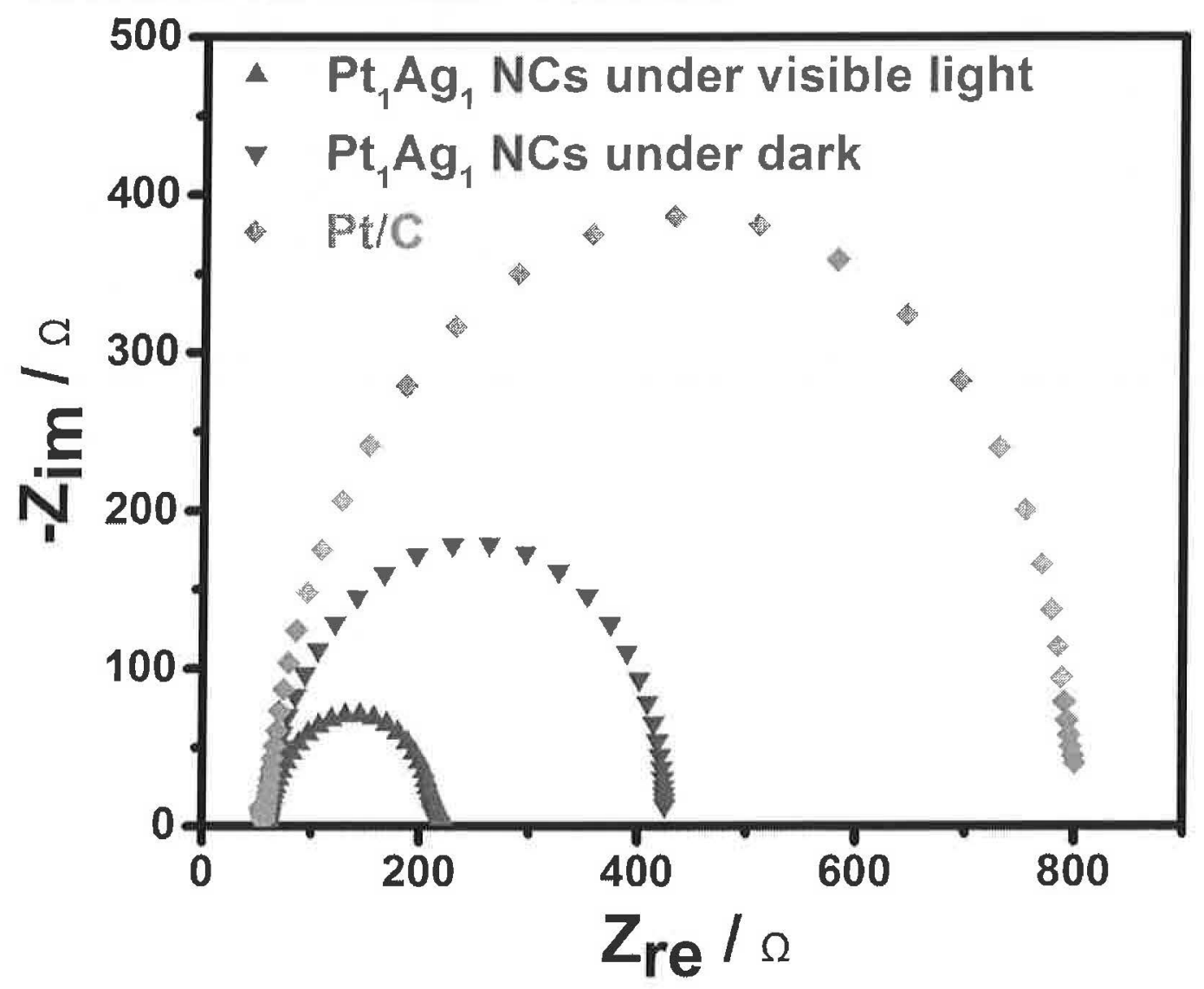


Fig.5 The Nyquist plots of commercial $\mathrm{Pt} / \mathrm{C}, \mathrm{Pt}_{1} \mathrm{Ag}_{1}$ hollow nanodendrites modified electrodes under visible light irradiation or dark conditions at the potential of $-0.2 \mathrm{~V}$.

Next, we have also conducted EIS at the potential of $-0.1 \mathrm{~V}$, for which the diameter is a crucial parameter, to evaluate the electrical resistance and conductivity of the as-prepared electrocatalysts. As it can be observed in Fig.5, the diameter impedance arc (DIA) of $\mathrm{Pt}_{1} \mathrm{Ag}_{1}$ hollow nanodendrites under visible light illumination is much smaller than that under dark conditions and that of the commercial $\mathrm{Pt} / \mathrm{C}$ catalyst. This indicated that $\mathrm{Pt}_{1} \mathrm{Ag}_{1}$ hollow nanodendrites nanocatalysts modified electrode possessed smaller electron transfer resistance. In addition, the best electrical conductivity under visible light illumination is attributed to the SPR effect and the charge transfer between Pt and Ag [35-39].

In general, the greatly enhanced electrocatalytic performances of Pt-Ag hollow nanodendrites towards EGOR can be mainly attributed to the following combined features: (1) the unique hollow dendritic nanostructures can efficiently provide high surface active areas available for the EG molecules [40]. (2) The electronic and synergistic effects originated from the $\mathrm{Pt}$ and $\mathrm{Ag}$ are also beneficial for enhancing their electrocatalytic activity and durability [41-45]. (3) Most importantly, the photoelectrical effects induced by SPR upon the visible light irradiation are crucial for the substantial enhancements of electrocatalytic performances towards EGOR [46].

\section{Conclusions}

In summary, a simple method has been successfully demonstrated for the synthesis of an advanced class of Pt-Ag photoelectrocatalysts. Owing to the unique hollow nanodendrite structure, as well as the synergistic and electronic effects between $\mathrm{Pt}$ and $\mathrm{Ag}$, the as-prepared $\mathrm{Pt}-\mathrm{Ag}$ hollow nanodendrite can expose more surface active area. In addition, it can display remarkable electrocatalytic activity towards EGOR with the unprecedentedly high mass and specific activities of 7045.2 $\mathrm{mA} \mathrm{mg}{ }^{-1}$ and $14.1 .1 \mathrm{~mA} \mathrm{~cm}^{-2}$. Furthermore, 6.2 and 7.0-fold enhancements were obtained compared to those of the commercial Pt/C. More significantly, owing to the SPR effects based on the Ag, the Pt-Ag hollow nanodendrites under the visible light irradiation also showed an enhancement of 1.7 times in catalytic activity than that 
under dark conditions. A number of excellent Pt-Ag photocatalysts have been prepared, the one we obtained is the best with both high catalytic activity and long-term stability, which can be well applied as highly efficient photoelectrocatalysts for fuel cells. This manuscript opens up a promising and novel approach for designing highly efficient photoelectrocatalysts towards liquid fuel electrooxidation and other chemical reactions, which would greatly alleviate the serious energy crisis and environment pollution.

\section{Acknowledgements}

This work was supported by the National Natural Science Foundation of China (Grant No. 51373111), the Suzhou Industry (SYG201636), the project of scientific and technologic infrastructure of Suzhou (SZS201708), the Priority Academic Program Development of Jiangsu Higher Education Institutions (PAPD).

\section{References}

[1] S. Linic, P. Christopher, D.B. Ingram, Plasmonic-metal nanostructures for efficient conversion of solar to chemical energy, Nature Mater. 10 (2011) 911-921.

[2] R. Jiang, B. Li, C. Fang, J. Wang, Metal/Semiconductor hybrid nanostructures for plasmon-enhanced applications, Adv. Mater. 26 (2014) 5274-5309.

[3] P. Christopher, H. Xin, S. Linic, Visible-light-enhanced catalytic oxidation reactions on plasmonic silver nanostructures, Nature Chem. 3 (2011) 467-472.

[4] P. Christopher, H. Xin, A. Marimuthu, S. Linic, Singular characteristics and unique chemical bond activation mechanisms of photocatalytic reactions on plasmonic nanostructures, Nature Mater. 11 (2012) 1044-1050.

[5] H. Yang, L.Q. He, Y.W. Hu, X. Lu, G.R. Li, B. Liu, B. Ren, Y. Tong, P.P. Fang, Quantitative Detection of Photothermal and Photoelectrocatalytic Effects Induced by SPR fromAu@Pt Nanoparticles, Angew. Chem. 54 (2015) 11462-11466.

[6] C. Clavero, Plasmon-induced hot-electron generation at nanoparticle/metal-oxide interfaces for photovoltaic and photocatalytic devices, Nature Photo. 8 (2014) 95-103. [7] S.K. Cushing, J. Li, F. Meng, T.R. Senty, S. Suri, M. Zhi, M. Li, A.D. Bristow, N. $\mathrm{Wu}$, Photocatalytic activity enhanced by plasmonic resonant energy transfer from metal to semiconductor, J. Am. Chem. Soc. 134 (2012) 15033-15041.

[8] Z. Zheng, T. Tachikawa, T. Majima, Plasmon-enhanced formic acid dehydrogenation using anisotropic Pd-Au nanorods studied at the single-particle level, J. Am. Chem. Soc. 137 (2015) 948-957.

[9] Z. Zhang, A. Li, S.W. Cao, M. Bosman, S. Li, C. Xue, Direct evidence of plasmon enhancement on photocatalytic hydrogen generation over $\mathrm{Au} / \mathrm{Pt}$-decorated $\mathrm{TiO}_{2}$ nanofibers, Nanoscale 6 (2014) 5217-5222.

[10] B.-H. Wu, W.-T. Liu, T.-Y. Chen, T.-P. Perng, J.-H. Huang, L.-J. Chen, Plasmon-enhanced photocatalytic hydrogen production on $\mathrm{Au} / \mathrm{TiO}_{2}$ hybrid 
nanocrystal arrays, Nano Energy 27 (2016) 412-419.

[11] Z. Lou, M. Fujitsuka, T. Majima, Pt-Au triangular nanoprisms with strong dipole plasmon resonance for hydrogen generation studied by single-particle spectroscopy, ACS nano 10 (2016) 6299-6305.

[12] H. Zhang, X. Fan, X. Quan, S. Chen, H. Yu, Graphene sheets grafted Ag@AgCl hybrid with enhanced plasmonic photocatalytic activity under visible light, Environ. Sci. Technol. 45 (2011) 5731-5736.

[13] K.M. Choi, D. Kim, B. Rungtaweevoranit, C.A. Trickett, J.T. Barmanbek, A.S. Alshammari, P. Yang, O.M. Yaghi, Plasmon-enhanced photocatalytic $\left.\mathrm{CO}_{2}\right)$ conversion within metal-organic frameworks under visible light, J. Am. Chem. Soc. 139 (2017) 356-362.

[14] S. Bai, X. Li, Q. Kong, R. Long, C. Wang, J. Jiang, Y. Xiong, Toward enhanced photocatalytic oxygen evolution: synergetic utilization of plasmonic effect and schottky junction via interfacing facet selection, Adv. Mater. 27 (2015) 3444-3452.

[15] F. Wang, C. Li, H. Chen, R. Jiang, L.D. Sun, Q. Li, J. Wang, J.C. Yu, C.H. Yan, Plasmonic harvesting of light energy for suzuki coupling reactions, J. Am. Chem. Soc. 135 (2013) 5588-5601.

[16] J. Xue, S. Ma, Y. Zhou, Z. Zhang, M. He, Facile Photochemical synthesis of $\mathrm{Au} / \mathrm{Pt} / \mathrm{g}-\mathrm{C}_{3} \mathrm{~N}_{4}$ with Plasmon-enhanced photocatalytic activity for antibiotic degradation, ACS Appl. Mater. Interfaces 7 (2015) 9630-9637.

[17] R. Shi, Y. Cao, Y. Bao, Y. Zhao, G.I.N. Waterhouse, Z. Fang, L.Z. Wu, C.H. Tung, Y. Yin, T. Zhang, Self-assembled $\mathrm{Au} / \mathrm{CdSe}$ nanocrystal clusters for plasmon-mediated photocatalytic hydrogen evolution, Adv. Mater. $29 \quad$ (2017) DOI: 10.1002/adma.201700803

[18] S. Liu, R. Jiang, P. You, X. Zhu, J. Wang, F. Yan, Au/Ag core-shell nanocuboids for high-efficiency organic solar cells with broadband plasmonic enhancement, Energy Environ. Sci. 9 (2016) 898-905.

[19] J. Huang, Y. Zhu, C. Liu, Y. Zhao, Z. Liu, M.N. Hedhili, A. Fratalocchi, Y. Han, Fabricating a homogeneously alloyed $\mathrm{AuAg}$ shell on Au nanorods to achieve strong, stable, and tunable surface plasmon resonances, Small 11 (2015) 5214-5221.

[20] A. Naldoni, F. Riboni, M. Marelli, F. Bossola, G. Ulisse, A. Di Carlo, I. Píš, S. Nappini, M. Malvestuto, M.V. Dozzi, R. Psaro, E. Selli, V. Dal Santo, Influence of $\mathrm{TiO}_{2}$ electronic structure and strong metal-support interaction on plasmonic $\mathrm{Au}$ photocatalytic oxidations, Catal. Sci. Technol. 6 (2016) 3220-3229.

[21] H. Xu, J. Wang, B. Yan, K. Zhang, S. Li, C. Wang, Y. Shiraishi, Y. Du, P. Yang, Hollow $\mathrm{Au}_{\mathrm{x}} \mathrm{Ag} / \mathrm{Au}$ core/shell nanospheres as efficient catalysts for electrooxidation of liquid fuels, Nanoscale 9 (2017) 12996-13003.

[22] H. Xu, J. Wang, B. Yan, S. Li, C. Wang, Y. Shiraishi, P. Yang, Y. Du, Facile construction of fascinating trimetallic PdAuAg nanocages with exceptional ethylene glycol and glycerol oxidation activity, Nanoscale 9 (2017) 17004-17012.

[23] Krittayavathananon A, Sawangphruk M, et al. Electrocatalytic oxidation of ethylene glycol on palladium coated on 3D reduced graphene oxide aerogel paper in alkali media: Effects of carbon supports and hydrodynamic diffusion. Electrochim Acta 2016;212;237-246. 
[24] Xu H, Yan B, Li S, Wang J, Song P, Wang C, et al. Highly open bowl-like PtAuAg nanocages as robust electrocatalysts towards ethylene glycol oxidation. J Power Sources. 2018;384:42-47.

[25] J. B. Xu, T. S. Zhao, Z. X. Liang, synthesis of active platinum-silver alloy electrocatalyst toward the formic acid oxidation reaction, J. Phys. Chem. C 112 (2008) 17362-17367

[26] Y.Y. Feng, G.R. Zhang, J.H. Ma, G. Liu, B.Q. Xu, Carbon-supported Pt^Ag nanostructures as cathode catalysts for oxygen reduction reaction, PCCP 13 (2011) 3863-3872.

[27] J. Fei, J. Li, Controlled preparation of porous $\mathrm{TiO}_{2}-\mathrm{Ag}$ nanostructures through supramolecular assembly for plasmon-enhanced photocatalysis, Adv. Mater. 27 (2015) 314-319.

[28] M. Zhu, C. Zhai, M. Sun, Y. Hu, B. Yan, Y. Du, Ultrathin graphitic $\mathrm{C}_{3} \mathrm{~N}_{4}$ nanosheet as a promising visible-light-activated support for boosting photoelectrocatalytic methanol oxidation, Appl. Catal. Environ. 203 (2017) 108-115.

[29] H. Xu, B. Yan, K. Zhang, J. Wang, S. Li, C. Wang, Y. Shiraishi, Y. Du, P. Yang, Ultrasonic-assisted synthesis of N-doped graphene-supported binary $\mathrm{PdAu}$ nanoflowers for enhanced electro-oxidation of ethylene glycol and glycerol, Electrochim. Acta 245 (2017) 227-236.

[30] Sawangphruk M, Krittayavathananon A, Chinwipas N. Ultraporous palladium on flexible graphene-coated carbon fiber paper as high-performance electro-catalysts for the electro-oxidation of ethanol. J Mater Chem A. 2013;1:1030-1034.

[31] H. Xu, K. Zhang, B. Yan, J. Wang, C. Wang, S. Li, Z. Gu, Y. Du, P. Yang, Ultra-uniform PdBi nanodots with high activity towards formic acid oxidation, J. Power Sources 356 (2017) 27-35.

[32] X. Weng, Q. Liu, J.J. Feng, J. Yuan, A.J. Wang, Dendrite-like PtAg alloyed nanocrystals: Highly active and durable advanced electrocatalysts for oxygen reduction and ethylene glycol oxidation reactions, J. Colloid Interface Sci. 504 (2017) 680-687.

[33] P. Song, L. Liu, J.-J. Feng, J. Yuan, A.-J. Wang, Q.-Q. Xu, Poly(ionic liquid) assisted synthesis of hierarchical gold-platinum alloy nanodendrites with high electrocatalytic properties for ethylene glycol oxidation and oxygen reduction reactions, Int. J. Hydrogen Energy 41 (2016) 14058-14067.

[34] Xu H, Song P, Fernandez C, Wang J, Zhu M, Shiraishi Y, et al. Sophisticated construction of binary $\mathrm{PdPb}$ alloy nanocubes as robust electrocatalysts toward ethylene glycol and glycerol oxidation. ACS Appl Mater Interfaces. 2018;10:12659-12665.

[35] G. Fu, H. Liu, N. You, J. Wu, D. Sun, L. Xu, Y. Tang, Y. Chen, Dendritic platinum-copper bimetallic nanoassemblies with tunable composition and structure: Arginine-driven self-assembly and enhanced electrocatalytic activity, Nano Res. 9 (2016) 755-765.

[36] H. Xu, B. Yan, J. Wang, K. Zhang, S. Li, Z. Xiong, C. Wang, Y. Shiraishi, Y. Du, P. Yang, Self-supported porous 2D AuCu triangular nanoprisms as model electrocatalysts for ethylene glycol and glycerol oxidation, J. Mater. Chem. A 5 (2017) 
15932-15939.

[37] M.S. Hamdy, M.A. Eissa, S.M.A.S. Keshk, New catalyst with multiple active sites for selective hydrogenolysis of cellulose to ethylene glycol, Green Chem. 19 (2017) 5144-5151.

[38] H. Xu, B. Yan, K. Zhang, J. Wang, S. Li, C. Wang, Z. Xiong, Y. Shiraishi, Y. Du, P. Yang, Sophisticated construction of hollow $\mathrm{Au}-\mathrm{Ag}-\mathrm{Cu}$ nanoflowers as highly efficient electrocatalysts toward ethylene glycol oxidation, ACS Sustain. Chem. Eng. 5 (2017) $10490-10498$.

[39] J. Liu, G. Xu, B. Liu, J. Zhang, A dendritic core-shell $\mathrm{Cu@PtCu} \mathrm{alloy}$ electrocatalyst resulting in an enhanced electron transfer ability and boosted surface active sites for an improved methanol oxidation reaction, Chem.1 Commun. 53 (2017) 7457-7460.

[40] X. Jiang, X. Yan, W. Ren, Y. Jia, J. Chen, D. Sun, L. Xu, Y. Tang, Porous $\mathrm{AgPt} @ \mathrm{Pt}$ nanooctahedra as an efficient catalyst toward formic acid oxidation with predominant dehydrogenation pathway, ACS Appl. Mater.Interfaces 8 (2016) 31076-31082.

[41] H. Xu, B. Yan, K. Zhang, J. Wang, S. Li, C. Wang, Y. Shiraishi, Y. Du, P. Yang, Facile fabrication of novel PdRu nanoflowers as highly active catalysts for the electrooxidation of methanol, J. Colloid Interface Sci. 505 (2017) 1-8.

[42] H. Xu, B. Yan, K. Zhang, C. Wang, J. Zhong, S. Li, P. Yang, Y. Du, Facile synthesis of Pd-Ru-P ternary nanoparticle networks with enhanced electrocatalytic performance for methanol oxidation, Int. J. Hydrogen Energy 42 (2017) 11229-11238. [43] C. Wang, R. Yue, H. Wang, C. Zou, J. Du, F. Jiang, Y. Du, P. Yang, C. Wang, Dendritic Ag@Pt core-shell catalyst modified with reduced graphene oxide and titanium dioxide: Fabrication, characterization, and its photo-electrocatalytic performance, Int. J. Hydrogen Energy 39 (2014) 5764-5771.

[44] C.T. Lin, M.H. Shiao, M.N. Chang, N. Chu, Y.W. Chen, Y.H. Peng, B.H. Liao, H.J. Huang, C.N. Hsiao, F.G. Tseng, A facile approach to prepare silicon-based Pt-Ag tubular dendritic nano-forests (tDNFs) for solar-light-enhanced methanol oxidation reaction, Nanoscale Res. Lett. 10 (2015) 74. DOI 10.1186/s11671-015-0791-9

[45] Xu H, Yan B, Zhang K, Wang J, Li S, Wang C, et al. Sub-5nm monodispersed $\mathrm{PdCu}$ nanosphere with enhanced catalytic activity towards ethylene glycol electrooxidation. Electrochim Acta. 2018;261:521-9.

[46] Xu H, Yan B, Zhang K, Wang J, Li S, Wang C, et al. Self-supported worm-like $\mathrm{PdAg}$ nanoflowers as efficient electrocatalysts towards ethylene glycol oxidation. ChemElectroChem. 2017;4:2527-2534. 
Fig.1 (a, b) Representative TEM images of $\mathrm{Pt}_{1} \mathrm{Ag}_{1}$ hollow nanodendrites with different magnifications. (c) HRTEM image of an individual $\mathrm{Pt}_{1} \mathrm{Ag}_{1}$ hollow nanodendrite. (d) XRD patterns of $\mathrm{Pt}_{1} \mathrm{Ag}_{1}$ hollow nanodendrites, $\mathrm{Pt}$ and $\mathrm{Ag}$. (e) The TEM-EDX elemental mapping, HAADF-STEM and corresponding (f) line-scan of individual $\mathrm{Pt}_{1} \mathrm{Ag}_{1}$ hollow nanodendrites for element distribution analyses.

Fig. 2 The XPS spectra of (a) $\mathrm{Pt} 4 \mathrm{f}$ and (b) $\mathrm{Ag} 3 \mathrm{~d}$ in $\mathrm{Pt}_{1} \mathrm{Ag}_{1}$ hollow nanodendrites. (c) UV-vis spectra of dendritic $\mathrm{Pt}_{1} \mathrm{Ag}_{1}$ hollow nanodendrites, and (d) photocurrent responses of $\mathrm{Pt}_{1} \mathrm{Ag}_{1}$ hollow nanodendrites towards EGOR in $1 \mathrm{M} \mathrm{EG}$ and $1 \mathrm{M} \mathrm{KOH}$ solution at a potential of $-0.2 \mathrm{~V}$ under visible light illumination. The illumination from a Xe lamp was interrupted every $100 \mathrm{~s}$.

Fig. 3 (a) $\mathrm{CV}$ curves of $\mathrm{Pt}_{1} \mathrm{Ag}_{1}, \mathrm{Pt}_{1} \mathrm{Ag}_{1.5}, \mathrm{Pt}_{1} \mathrm{Ag}_{0.5}$ hollow nanodendrites and commercial $\mathrm{Pt} / \mathrm{C}$ in 1 M KOH solution. (b) The calculated ECSA of $\mathrm{Pt}_{1} \mathrm{Ag}_{1}, \mathrm{Pt}_{1} \mathrm{Ag}_{1.5}, \mathrm{Pt}_{1} \mathrm{Ag}_{0.5}$ hollow nanodendrites and commercial $\mathrm{Pt} / \mathrm{C}$. (c) $\mathrm{CV}$ curves of $\mathrm{Pt}_{1} \mathrm{Ag}_{1}$ hollow nanodendrites under visible light illumination and dark, as well as commercial $\mathrm{Pt} / \mathrm{C}$. (d) The calculated specific and mass activities $\mathrm{Pt}_{1} \mathrm{Ag}_{1}$ hollow nanodendrites under visible light illumination and dark, as well as commercial $\mathrm{Pt} / \mathrm{C}$ towards EGOR. (e) $\mathrm{CV}$ curves of $\mathrm{Pt}_{1} \mathrm{Ag}_{1.5}, \mathrm{Pt}_{1} \mathrm{Ag}_{0.5}$ hollow nanodendrites towards EGOR under visible light illumination and dark. (f) The calculated specific and mass activities of $\mathrm{Pt}_{1} \mathrm{Ag}_{1.5}$, $\mathrm{Pt}_{1} \mathrm{Ag}_{0.5}$ hollow nanodendrites towards EGOR under visible light illumination and dark condition were illustrated. These electrochemical measurements were repeated five times to achieve precise results.

Fig.4 Durability comparison of ( $\mathrm{a}$ and $\mathrm{b}$ ) $\mathrm{Pt}_{1} \mathrm{Ag}_{0.5}$ hollow nanodendrites under visible light irradiation, ( $\mathrm{c}$ and $\mathrm{d}$ ) $\mathrm{Pt}_{1} \mathrm{Ag}_{0.5}$ hollow nanodendrites under ambient reaction and (e and $\mathrm{f}$ ) commercial $\mathrm{P} t / \mathrm{C}$ for the successive CVs of $200^{\text {th }}, 300^{\text {th }}, 400^{\text {th }}$ and $500^{\text {th }}$ cycles together with the retained specific and mass activities. These electrochemical measurements were repeated five times to achieve precise results. 
Fig.5 The Nyquist plots of commercial $\mathrm{Pt} / \mathrm{C}, \mathrm{Pt}_{1} \mathrm{Ag}_{1}$ hollow nanodendrites modified electrodes under visible light irradiation or dark conditions at the potential of $-0.2 \mathrm{~V}$. 
Fig.1
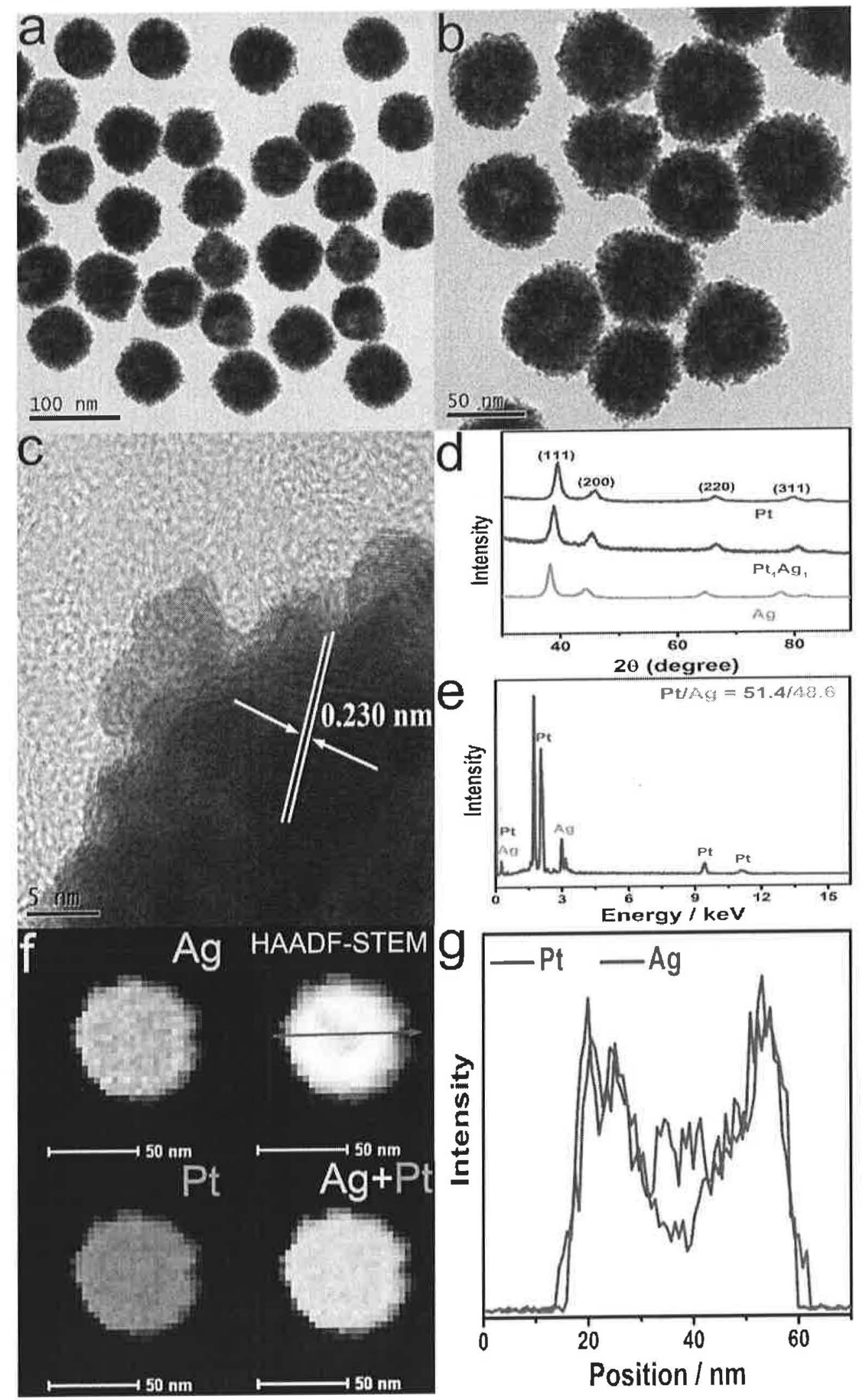
Fig.2
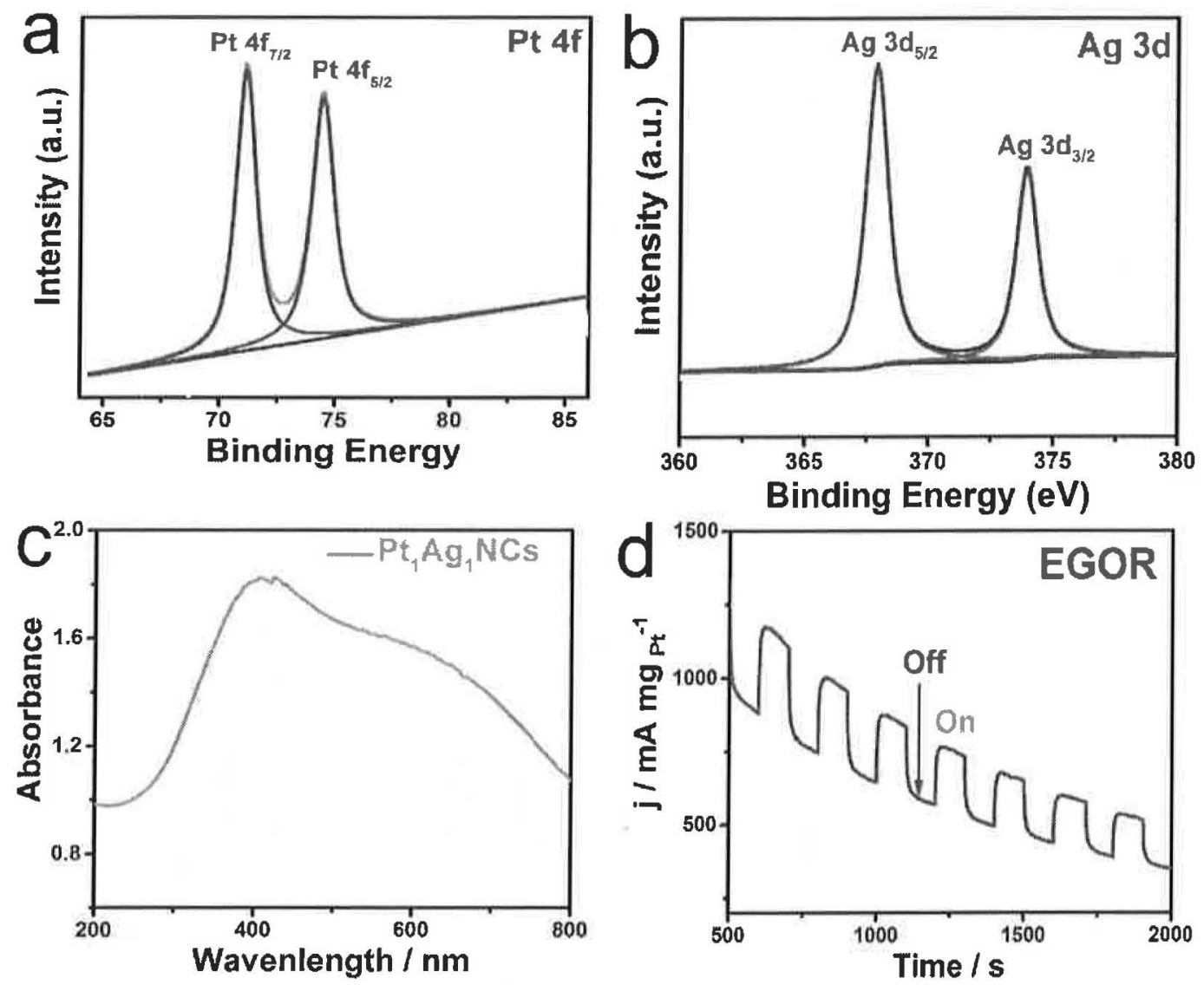
Fig.3
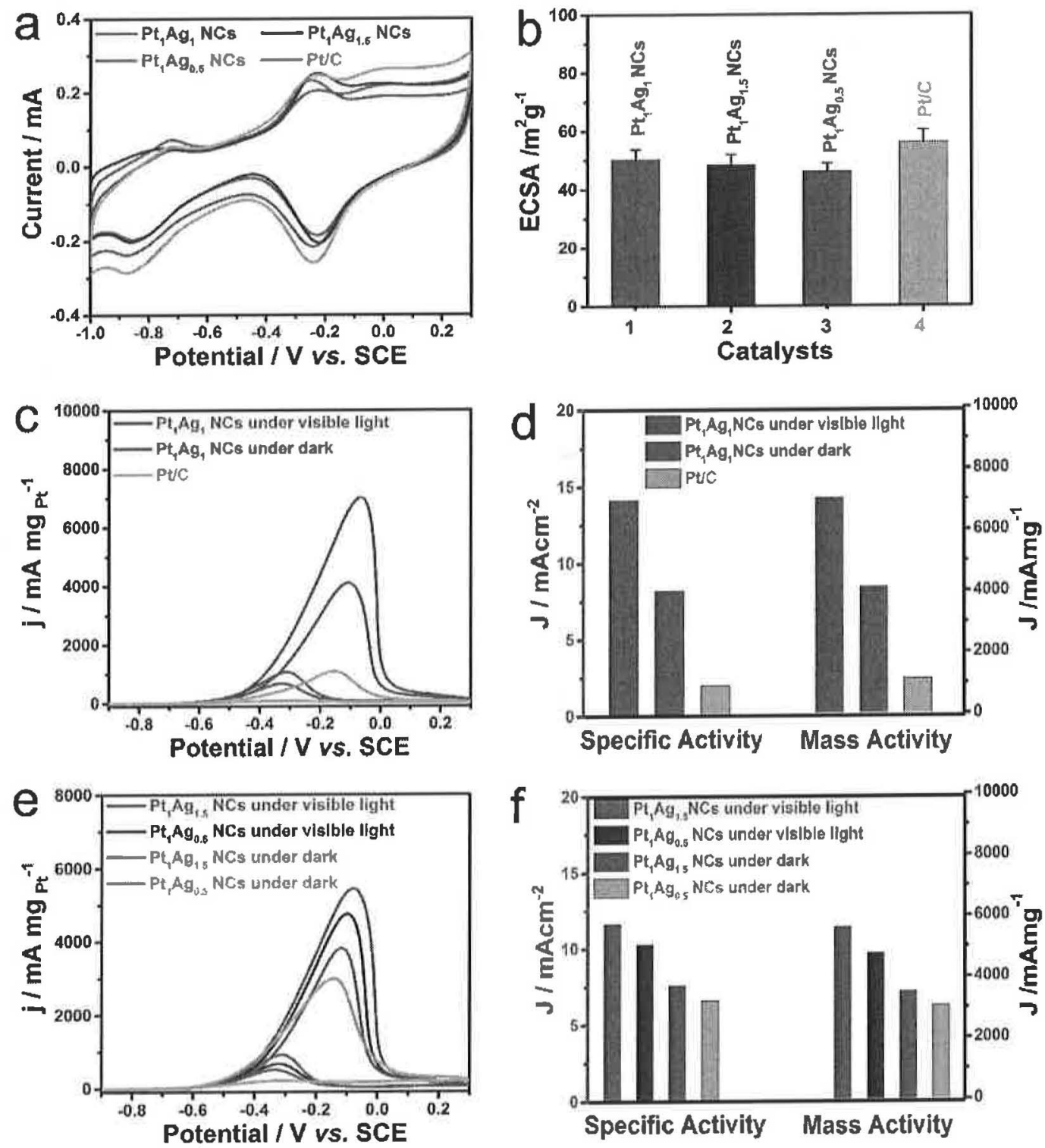
Fig.4
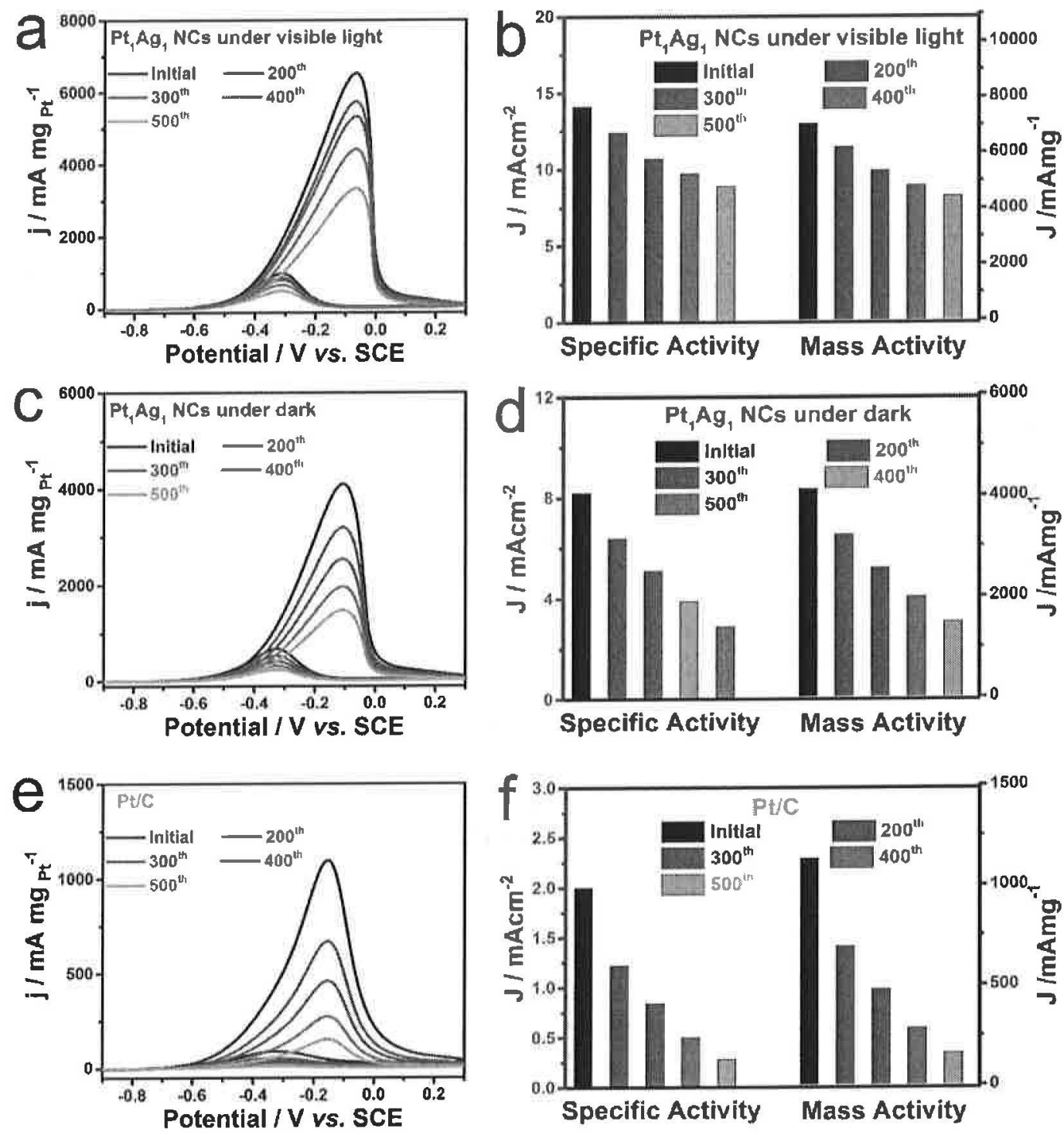
Fig.5

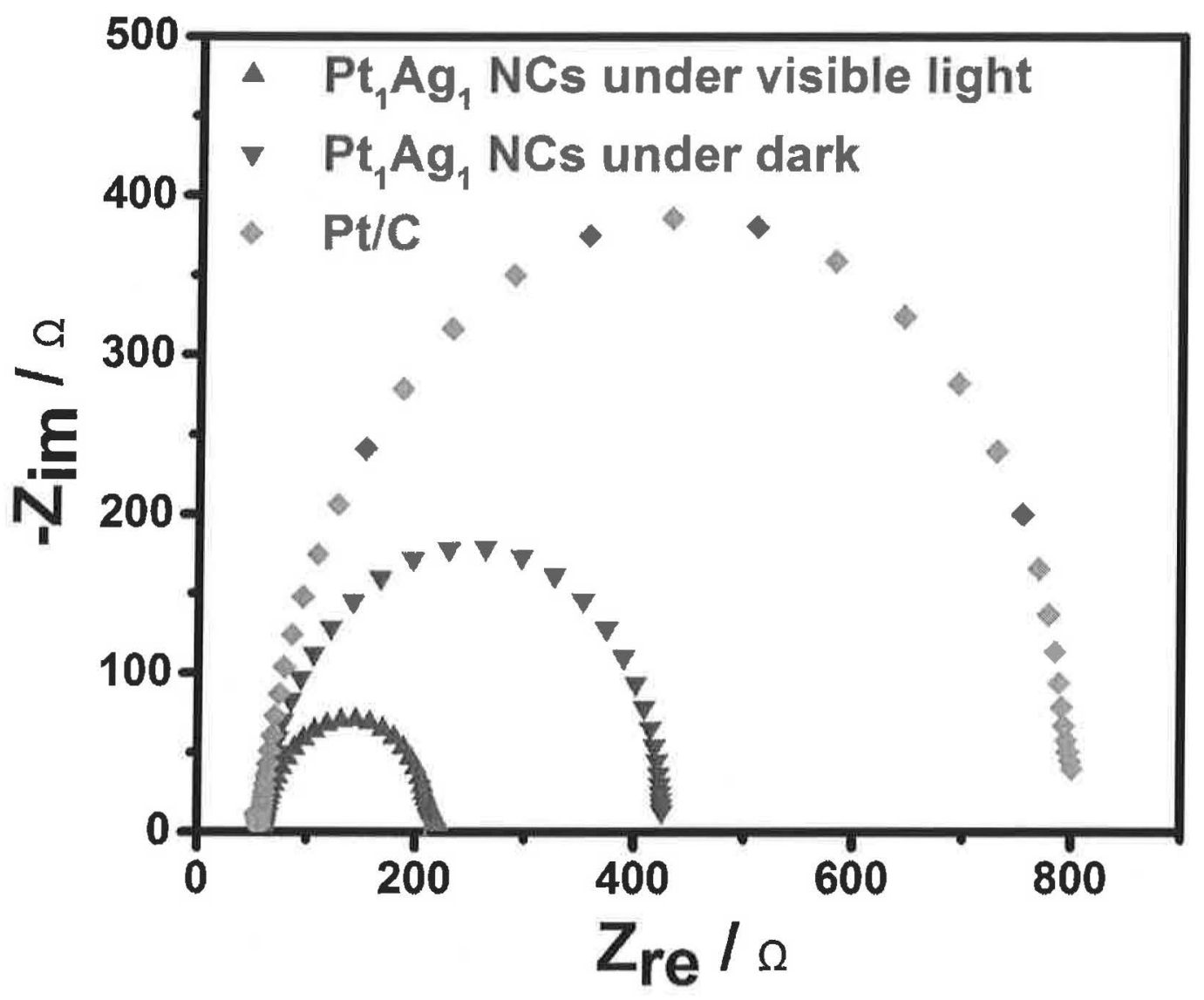




\section{Supplementary Material}

Click here to download Supplementary Material: Supporting Information.docx 


\section{Graphical Abstract}

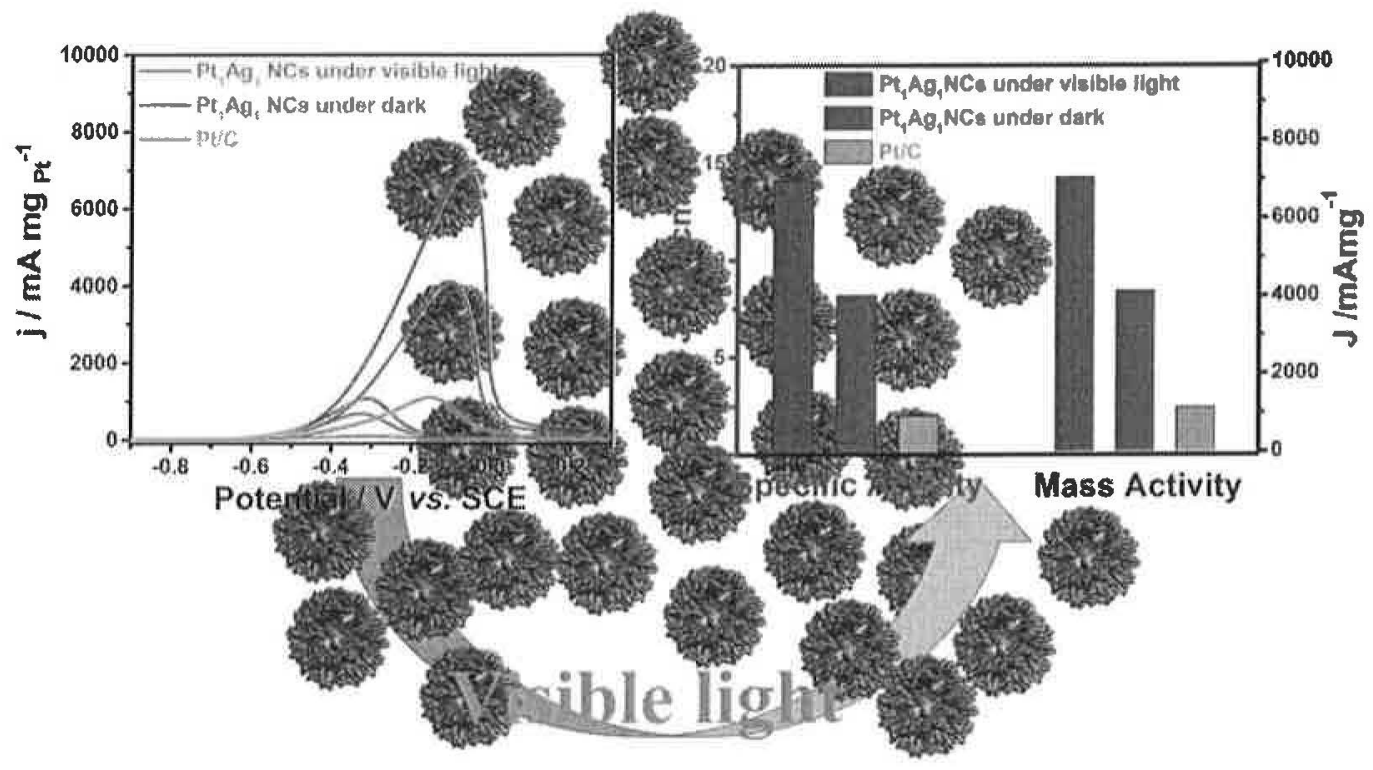

